$\square$ 증 례 $\square$

$$
\text { 굴곡성 기관지경하에서 치료한 기관지결석증 } 1 \text { 예 }
$$

한양대학교 의과대학 내과학교실

$$
\begin{gathered}
\text { 고 윤 석·최 진·한 동 수 } \\
\text { 박 성 수·이 정 희 }
\end{gathered}
$$

$=$ Abstract $=$

\title{
A Case of Broncholithiasis, which was Treated by Flexible Bronchofiberscopy
}

\author{
Youn Suck Koh, M.D., Jin Choi, M.D., Dong Soo Han, M.D \\ Sung Soo Park, M.D. and Jung Hee Lee,M.D.
}

Department of Internal Medicine, College of Medicine, Han Yang University, Seoul, Korea

Broncholithiasis is rare but troublesome disease that can cause life-threatening complications.

Broncholithiasis is clinically important because calcified nodes may cause a variety of nonspecific signs and symptoms of respiratory diseases prior to the onset of lithoptysis.

We were able to see the broncholith by the flexible bronchofiberscopy at the opening of left upper lobal bronchus with almost complete obstruction in a 30-year-old woman.

Removal of calcareous material was successfully accomplished by the flexible bronchofiberscopy without complications.

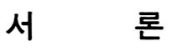

기관지결석은 결석증이 기관지나 기관지와 교통하고 있는 공동내에 존재하는 경우를 말한다.

기관지결석증은 드문질환이며, 때로는 생명을 위협하 는 중대한 합병증을 초래할 수도 있다.

저자들은 발작성 기침 및 혈담을 주소로 본원 내과에 내원한 30 세 여자환자에서 굴곡성 기관지 내시경검사상 좌측상엽기관지를 폐쇄하고 있는 기관지결석을 발견 생 검겸자로 내시경하 제거한 1 례를 경험하였기에 보고하는 바이다.

\section{증 례}

환 자: 강아자, 여자, 30 세

주 소 : 기침, 혈담.

현병력 : 내원 11 개월전부터 기침, 오한 및 소량의 각
혈이 자주 있었다.

개인의원에서 만성기관지염 의심하에 가료를 받았으 나, 증상의 호전은 없었다. 입원 1 개월전부터 혈담이 다 시 시작되면서 악화되어 본원 내과에 입원하였다.

개인력 및 과거력 : 가정주부로 흡연력은 없었다.

가족력 : 모친이 20 년전 폐결핵으로 진단후 1 년간 가료 하였음.

이학적 소견 : 영양상태 및 전신상태는 양호하였으며, 입원당시 혈압은 $130 / 80 \mathrm{mmHg}$ 였고, 맥박수 78 회/분, 호흡수 20 회/분, 체온은 $36.7^{\circ} \mathrm{C}$ 였다. 좌측 폐상부의 호 흡음이 감소되어 있었다.

검사소견 : 혈색소는 $13.9 \mathrm{gm} \%$, 백혈구 $17,200 /$ $\mathrm{mm}^{3}$, polys $73 \%$, band neutrophils $7 \%$, lymphocyte $16 \%$, monocyte $3 \%$, eosinophils $1 \%$, ESR $9 \mathrm{~mm} / \mathrm{hr}$, 혈중 $\mathrm{CEA}$ 치 $2.5 \mathrm{ng} / \mathrm{ml}$ 였다. 요검사, 대변내 기생충 및 잠혈검사, 혈청전해질검사, 간기능검사 소견등 모두 정 상범위였다. 심전도검사도 정상이었다. 굴곡성 기관지경 의 촬과물 및 세척액내 $\mathrm{AFB}$ 도말검사와 진균도말검사, 

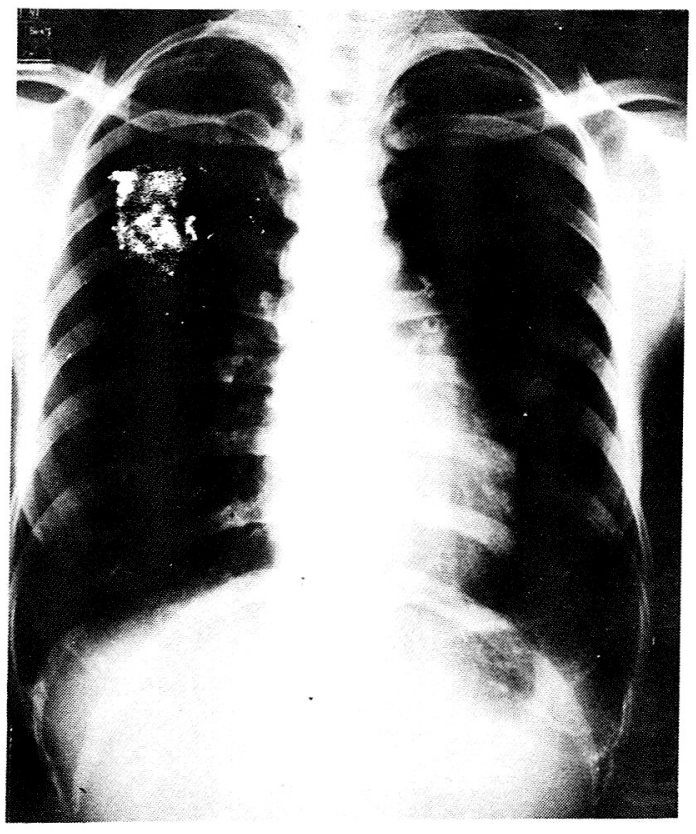

Fig. 1-1. The chest $X$-ray show perihilar dense calcifications with collapse of lingular segment of left lobe.

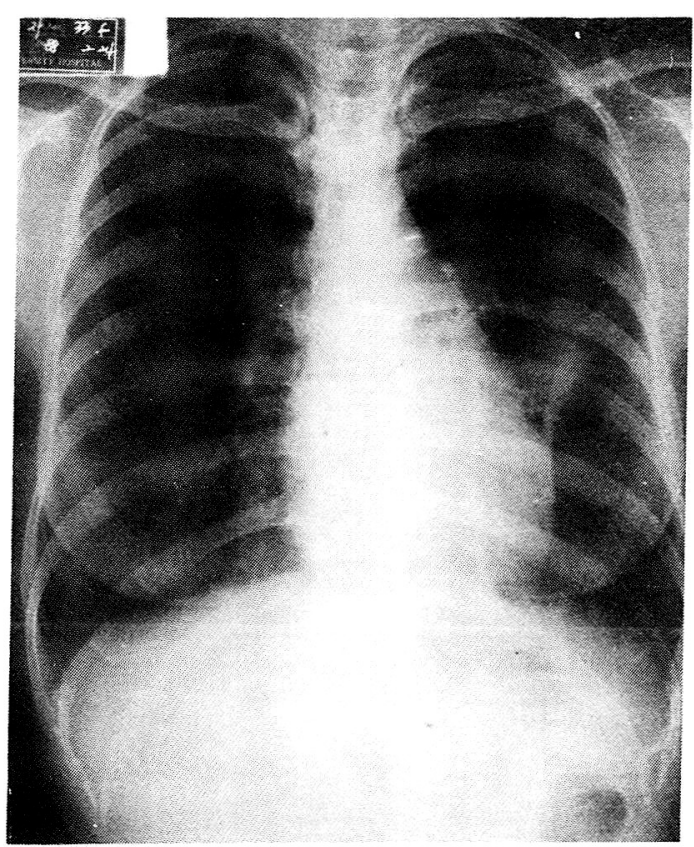

Fig. 1-2. After removal of broncholith, decreased perihilar calcifications are seen.
진균배양검사 모두 음성이었고, 세포학적 검사도 악성세 포는 발견하지 못하였다.

흉부X-선 소견 : 폐문주위의 석회화음영들과 좌측 폐 상엽의 무기폐소견이 있었다(Fig. 1-1). 또한 굴곡성 기 관지경 하에 결석을 제거후 추적 흥부 X-선챨영을 하였 다(Fig. 1-2).

굴곡성 기관지경 소견 : 좌측 폐상엽의 기관지 개구부 가 결석에 의하여 폐쇄되었으며, 결석표면은 견고하고 불 규칙하였다. 또한 결석은 느슨하였고, 생검겸자(鉗字)에

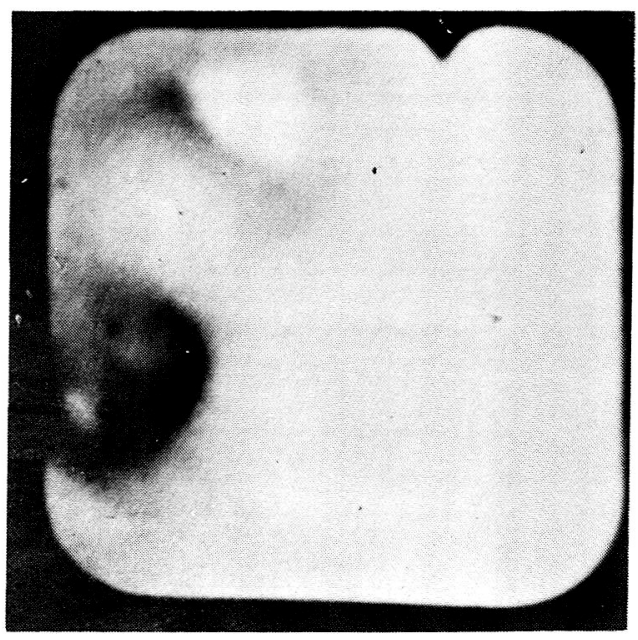

Fig. 2-1. The upper lobe of left lung is almost totally obstructed by loose and mobile oroncholith.

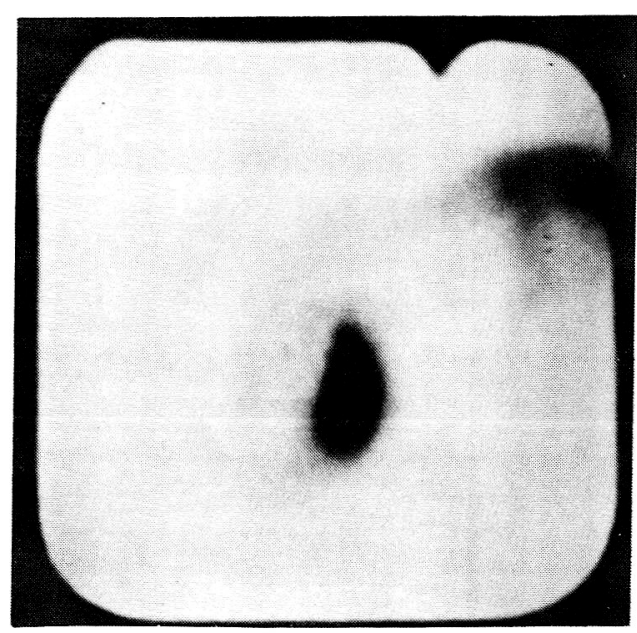

Fig. 2-2. After removal of broncholith, the opening of upper lobe is seen. 


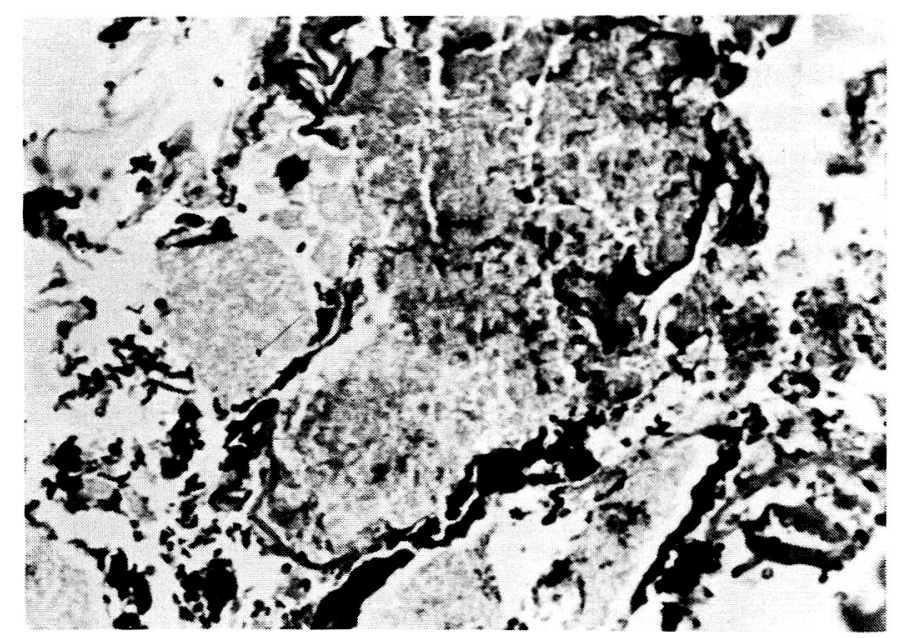

Fig. 3. The section of broncholith showes central amorphous necrotic areas surrounded by calcific area after decalcification. (H\&E, $\times 100)$.

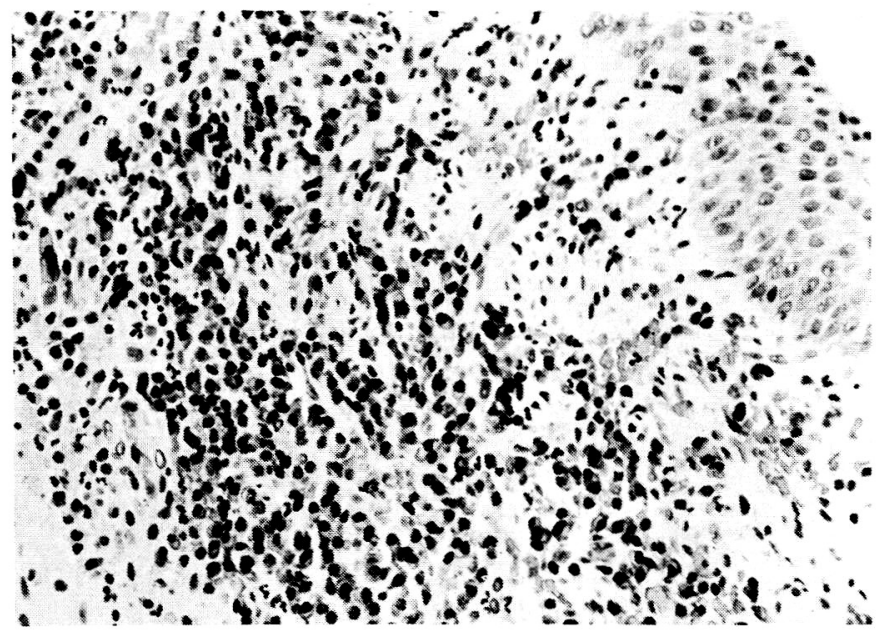

Fig. 4. It showes bronchial mucosa with squamous metaplasia and acute and chronic inflammatory infiltrate (H\&E, x200).

의해 움직였다 (Fig. 2-1).

기관지결석은 생검겸자로 쉽게 제거되었으며, 제거된 기관지결석의 크기는 $0.3 \times 0.3 \mathrm{~cm}$ 였다(Fig. 2-2). 결석 제거후 주위조직을 생검하였다.

병리학적 소견 : 결석은 육안적으로 직경 $0.3 \mathrm{~cm}$ 의 석 회화된 결절로, 중심부위에 괴사부위가 있었다(Fig. 3). 결석에 대한 AFB 염색, PAS 염색, GMS(Gomori's methenamine silver stain) 염색상 모두 음성이었다. 결 석주변 조직의 생검소견은 편평화생(化生) 및 점막하조
직에 임파구와 형질세포로 구성된 심한 염증세포의 침윤 이 있었다(Fig. 4).

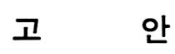

기관지 결석증의 발생빈도는 육아종성폐감염의 빈도등 과 연관될 것으로 추측되나, 정확한 빈도는 알려져 있지 않다. 연령은 60 대에 호발하고, 발생부위는 우측이 좌측 보다 2 배로 발생빈도가 많다 ${ }^{123}$. 기관지결석증의 원인은 
첫째, 결핵과 같은 육아종성감염 또는 히스토플라스마 증, 드물게는 방선균증(actinomycosis), 콕씨디오이데 스진균증 및 크립토콕스증과 같은 진균감염에 의한 종격 동이나 폐문부임파절의 석회화, 둘째, 이전에 흡입된 이 물질(異物質) 주위의 석회화, 세째, 노화에 따른 기관지 벽에서 형성된 칼슘이 떨어져 나오는 경우, 그리고 드물 게는 규폐증에 의해 발생될 수 있다 ${ }^{2,4}$. . 기관지결석의 정확한 생화학적기전은 알려져 있지 않지만, 알칼리성조 직내 칼슘염의 침강과 관련이 있다. 또한 여러가지 원인 들에 의하여 형성된 칼슘염이 호흡이나 심장의 박동에 의 해 침착된 임파선으로부터 주위조직으로 이동하며, 대개 는 기관지로 배출되나 때로는 식도나 폐혈관과 교통된 다9). 기관지결석의 화학적성분은 $85 \sim 90 \%$ 의 칼슘인산 염과 $10 \sim 15 \%$ 의 칼슘탄산염으로 구성되어 있다 ${ }^{1)}$. 기관 지결석증의 흔한 임상증상은 기관지결석에 의한 기관지 미란과 기관지압박과 관계가 있다. 기침, 각혈, 발열, 화 농성객담 및 홍통등이다 ${ }^{2,8 ~ 10)}$. 기관식도루가 형성되어 있 으면 기침은 심하고, 오래동안 계속된다2).

각혈은 환자의 $48.4 \%$ - $66.7 \%$ 에서 나타나며, 본예에 서도 기침 및 각혈의 주소가 있었다. 증상기간은, 1 개월 미만에서 20년이상까지 보고되어 있으나, 평균증상기간 은 2 5년이다 ${ }^{1,10,11)}$. 기관지결석에 의하여 부분폐쇄가 있을시 천식음을 들을 수 있기 때문에 기관지 천식으로 오진될 수도 있다2). 진단은 임상증상, 단순흥부 X-선촬 영, 단층성챨영법, 기관지조영술, ㅎㅎㅇ부전산화 단층챨영, 기관지내시경이 이용되며, 기관식도루가 의심되면, 식도 바륨찰영이 도움이된다. 단순흉부 X-선에서 흔히 폐실 질부의 병변을 초래하여 기관지암이나 폐염을 의심하는 경우도 많다. 그러나 기도나 주기관지에 인접한 석회화 된 임파절소견, 폐문부나 종격동의 석회화와 함께 그 이 하 부위의 폐허탈이나 폐실질부의 경화양상이 있으면 모 든예에 있어서 기관지결석증의 가능성을 생각하여야한 다 ${ }^{12)}$. 단층성쵤영법은 조밀한 염증성반응으로 인한 단순 홍부 X-선상 발견치 못하는 석회화의 발견 및 해부학적 상관관계를 아는데있어 도움을 준다. 기관지결석증의 기 관지경검사 소견은 기관 및 기관지의 의곡(歪曲), 기관 지협착증, 폴립양 육아조직소견, 기관지벽을 침식하는 탄분침착결절, 기관지내 염증소견 및 기관지결석이 직접 확인되는 경우등이다2,9). 경직성 기관지경으로 $57 \%$ 에서 굴곡성 기관지경으로는 $44.4 \%$ 에서 기관지결석을 직접 확인할 수 있다 ${ }^{1,2,10)}$.
훙부 전산화 단층촬영법은 단층성촬영법에 비해 방사 선노출이 적고 칼슘화된 다른 부위도 찾아낼 수 있는 이 점이 있다. 기관지경검사와 향부 전산화 단층 촬영법을 병행할시 $100 \%$ 진단할수 있다. 기관지 조영술을 시행한 23 예중 21예에서 이상소견이 있으며 ${ }^{2)}$, 적절한 폐절제술 을 계획하는 환자에서 시행한다. 절제된 조직의 병리학 적소견은 만성염증소견이 가장 많으며, 섬유화, 치유된 육아종, 기관지결석내에 탄분침착증 및 육아종성 변화, 기관지벽 주위에 만성염증세포침윤으로 섬유화 및 기관 지 확장증 소견들이 있다 ${ }^{1,9)}$. 절제된 임파절이나 폐조직 내에서 결핵이나 진균의 균주를 발견하는 것은 드물며 기 관지결석 자체에서는 발견되지 않는다. $\operatorname{Bech}^{13)}$ 은 30.8 $\%$ 에서 활동성 결핵이 있었다 하였다. 본예에서도 기관 지결석 자체에서 결핵균이나 진균은 발견되지 않았다. 기 관지결석증의 합병증은 기관식도루, 대동맥기관루, 늑막 으로 미란이다 ${ }^{14,15)}$. 치료목적은 기관지결석을 제거하고, 불가역으로 손상받은 기관지나 폐실질부를 가능한한 정 상 폐조직으로 유지하는데 있다9). 치료방법은 결석의 크 기, 위치, 합병증의 유무, 및 동반된 증상의 정도에 따 라 달라지나 주요증상이 없으면 관찰하며, 자연배출되기 를 기다린다. 기관지 결석증의 $33 \sim 50 \%$ 에서 객담내로 결 석이 배출된다. 기관지결석이 내시경상 직접 볼 수 있고, 느슨하고, 움직일시 기관지경하에서 제거할 수 있다. Arrigon등르는 $64 \%$ 에서, Moerch등 ${ }^{10)}$ 은 $87 \%$ 에서 각각 기관지경하에서 제거하였다. 본예에 있어서도 기관지결 석이 느슨하고, 움직여서 굴곡성 기관지경하에서 제거하 였다. 무리하여 기관지결석을 기관지경하에서 제거하는 경우 기관지훙막루, 기관식도루나, 주위 큰 혈관사이에 교통이된 경우 심한 출혈을 유발시킬 수 있다3,8 10).

병용할 수 있는 비수술적 처치로는 기관지내 충분한 습 윤화, 항생제 및 진해 거담제를 사용할 수 있다. 개홍술 의 적응증은 기관식도루나 대동맥기관루가 있을 경우, 각 혈이 지속적으로 반복되거나, 폐실질부의 화농, 및 폐암 이 의 심되는 경우이며, 수술방법은 분절절제술이 가장 흔 한 외과적 방법이다.

Arrigoni등)은 폐암과 동반된 기관지결석증 3 예를 보 고하였고, Trastek등9)은 기관지결석증 52예중 3예 (6.1 $\%)$ 에서 폐암이 발생하고, 이중 2 예는 결석이 존재한 동 일한 위치에 발생하였다 하였으나, 폐암과 기관지결석사 이의 인과관계는 불분명하다. 


\section{결 론}

저자들은 발작성기침과 각혈을 주소로 내원한 30 세여 자환자에서 단순홍부 $\mathrm{X}$-선상에서 폐분절의 허탈이 나타 나 시행한 굴곡성 기관지경하에서 기관지결석을 직접 확 인하고 생검겸자(鉗字)로 제거한 1예를 경험하였기에 문 헌고찰과 함께 보고하는 바이다.

\section{REFERENCES}

1) Arrigoni MG, Bernatz PE, Donoghue FE: Broncholithiasis. J Thorac Cardiovasc Surg 62:231, 1971

2) Faber LP, Jensik RJ, Chawla SK, Kittle DF: The surgical implication of broncholithiasis. J Thorac Cardiovasc Surg 70:779, 1975

3) Dixon GF, Donnerberg RL, Schonfeld SA, Whitcomb ME: Clinical commentary: Advances in diag. nosis and treatment of broncholithiasis. Am Rev Respir Dis 129:1028, 1984

4) Wells HG: Calcification and ossification. Arch Intern Med 7:721, 1911

5) Groves LK, Effler DB: Broncholithiasis: A reveiw of twenty-seven cases. Am Rev Respir Dis 73:19, 1956

6) Baum GL, Bernstein IL, Schwarz J: Broncholithiasis produced by histoplasmosis. Am Rev Respir Dis 77: 162, 1958

7) Uragoda CG: Broncholithiasis secondary to intrapleural calcification. Br Med J 2:1635, 1966

8) Carasso B, Couropmitree C, Heredia R: Egg-shell calcification causing bronchoesophageal fistula. Am Rev Respir Dis 108:1384, 1973

9) Trastek VF, Pairolero PC, Ceithaml EL, Piehler JM, Payne WS, Bernatz PE: Surgical management of broncholithiasis. J Thorac Cardiovasc Surg 90: 842,1985

10) Moersch HJ, Schmidt HW: Scientific papers of The American Bronchoesophagologica; Association. XXXIX Broncholithiasis. Ann Otol Rhinol Laryngol 68:548, 1959

11) Weed LA, Andersen HA: Etiology of broncholithiasis. Dis Chest 37:270, 1960

12) Lillington GA: A diagnostic approach to chest diseases. 3rd ED Baltimore: Williams \& Wilkins, 1987, p194

13) Bech K: Broncholithiasis. Nord Med 30:810, 1946

14) Bollengier E, Guernsey JM: Broncholithiasis with aortotracheal fistula. J Thorac Cardiovasc Surg 68: 588, 1974

15) Dias AR, Zerbini EJ, Curi N: Pleural stone. J Thorac Cardiovasc Surg 56:120, 1968 